\title{
Synthesis of ZIF-67@ZIF-8 with Core-shell Structure for Enhancing Epoxy Coating Corrosion Protection Property on Magnesium Alloy
}

\author{
Kun Cao ${ }^{1}$, Leilei $\mathrm{Yu}^{1}$, Xinlan Liu ${ }^{1}$, Yanqiu Yang ${ }^{1}$, Fubin $\mathrm{Ma}^{2, *}$ \\ ${ }^{1}$ Department of Chemistry \& Chemical Engineering, Neijiang Normal University, Neijiang, Sichuan, \\ 641112, PR China \\ ${ }^{2}$ Institute of Oceanology, Chinese Academy of Sciences, Qingdao, 266000, China \\ *E-mail: kevin_cao0811@126.com
}

doi: $10.20964 / 20201.03 .13$

Received: 1 November 2020 / Accepted: 14 December 2020 / Published: 31 January 2021

\begin{abstract}
Nanocontainers with corrosion inhibitors are an effective means to protect metals from corrosion. However, such coatings need to release the inhibitors rapidly to form an on-demand barrier on the metal surface, whereas coating damage needs to be minimized to prevent excessive leakage. Herein, this function is achieved by ZIF-67@ZIF-8 nanoparticles, a metal organic frame material with core-shell structure, by acting as a functional filler. The structure and composition of ZIF-67 and ZIF-67@ZIF-8 nanoparticles are assessed by TEM, SEM and XRD. The findings of UV spectroscopy and immersion experiments show that ZIF-67@ZIF-8 nanoparticles rapidly release 2-MI to the damaged area of the metal surface in acid conditions. In addition, in a neutral environment, only limited amounts of 2-MI (less than 4\%) are released. The coating has high corrosion resistance after immersion for $120 \mathrm{~h}$ in acidic condition, as exhibited by EIS, and thus potential application value.
\end{abstract}

Keywords: core-shell structure; metal organic framework; ZIF-67@ZIF-8; anticorrosion coating

\section{$\underline{\text { FULL TEXT }}$}

(C) 2021 The Authors. Published by ESG (www.electrochemsci.org). This article is an open access article distributed under the terms and conditions of the Creative Commons Attribution license (http://creativecommons.org/licenses/by/4.0/). 